Mark C. Johnson, $\mathrm{PhD}$

Emily R. Pierson, $\mathrm{PhD}$

Andrew J. Spieker, BS

A. Scott Nielsen, MD

Sylvia Posso, CCRC

Mariko Kita, MD

Jane H. Buckner, MD

Joan M. Goverman, PhD

Correspondence to

Dr. Goverman:

goverman@uw.edu
Supplemental data at Neurology.org/nn

\section{Distinct T cell signatures define subsets of patients with multiple sclerosis} OPEN

\section{ABSTRACT}

Objective: We investigated T cell responses to myelin proteins in the blood of healthy controls and 2 groups of patients with relapsing-remitting multiple sclerosis (RRMS) who exhibited lesions either predominantly in the brain or predominantly in the spinal cord in order to assess whether distinct neuroinflammatory patterns were associated with different myelin protein-specific $T$ cell effector function profiles and whether these profiles differed from healthy controls.

Methods: Peripheral blood mononuclear cells were obtained from patients with brain-predominant RRMS, patients with spinal cord-predominant RRMS, and age-matched healthy controls and analyzed by enzyme-linked immunosorbent spot assays to quantify interferon gamma-secreting (Th1) and interleukin 17-secreting (Th17) cells responding directly ex vivo to myelin basic protein (MBP) and myelin oligodendrocyte glycoprotein (MOG).

Results: Although MBP and MOG elicited different responses, patients with multiple sclerosis (MS) who had spinal cord-predominant lesions exhibited significantly higher Th17:Th1 ratios in response to both MBP and MOG compared to patients with brain-predominant MS. Incorporating the cytokine responses to both antigens into logistic regression models showed that these cytokine responses were able to provide good discrimination between patients with distinct neuroinflammatory patterns.

Conclusions: Our findings suggest that the localization of lesions within the brain vs the spinal cord in patients with MS is associated with different effector T cell responses to myelin proteins. Further investigation of the relationship between $T$ cell effector function, antigen specificities, and lesion sites may reveal features of pathogenic pathways that are distinct to patients with different neuroinflammatory patterns. Neurol Neuroimmunol Neuroinflamm 2016;3:e278; doi: $10.1212 / \mathrm{NXI} .0000000000000278$

\section{GLOSSARY}

AUC = area under the curve; $\mathbf{B R I}=$ Benaroya Research Institute; $\mathbf{E A E}=$ experimental autoimmune encephalomyelitis; $\mathbf{H C}=$ healthy control; IFN- $\gamma=$ interferon gamma; IL-17 = interleukin 17; MBP = myelin basic protein; MOG = myelin oligodendrocyte glycoprotein; $\mathbf{M S}$ = multiple sclerosis; PBMC = peripheral blood mononuclear cell; RRMS = relapsing-remitting multiple sclerosis.

Inflammatory lesions and plaques of demyelination are hallmark features of multiple sclerosis (MS). Most patients with relapsing-remitting MS (RRMS) exhibit lesions disseminated predominantly in the brain. In up to 5\% of patients with RRMS, however, lesions are localized primarily within the spinal cord instead of the brain. ${ }^{1,2}$ Spinal cord lesions often affect motor function and mobility, typically resulting in a higher degree of disability. ${ }^{3}$

In experimental autoimmune encephalomyelitis (EAE), several studies have linked different immune mediators with preferential induction of brain vs spinal cord inflammation. For example, expression of neutrophil chemoattractants induced by interleukin 17 (IL-17) signaling has been associated with brain inflammation, ${ }^{4,5}$ while interferon gamma (IFN- $\gamma$ ) signaling has been

\footnotetext{
From the Departments of Immunology (M.C.J., E.R.P., J.M.G.) and Biostatistics (A.J.S.), University of Washington, Seattle; Neuroscience Institute (A.S.N., M.K.), Virginia Mason Medical Center, Seattle; and Translational Research Program at the Benaroya Research Institute at Virginia Mason (S.P., J.H.B.), Seattle, WA.

Funding information and disclosures are provided at the end of the article. Go to Neurology.org/nn for full disclosure forms. The Article Processing Charge was paid by the authors.

This is an open access article distributed under the terms of the Creative Commons Attribution-NonCommercial-NoDerivatives License 4.0 (CC BY-NC-ND), which permits downloading and sharing the work provided it is properly cited. The work cannot be changed in any way or used commercially.
} 
shown to promote spinal cord inflammation. ${ }^{6}$ We previously demonstrated that parenchymal brain inflammation in EAE was enhanced when the ratio of IL-17-secreting $\mathrm{T}$ cells (Th17 cells) to IFN- $\gamma$-secreting $\mathrm{T}$ cells (Th1 cells) infiltrating the CNS was $\geq 1$. When the Th17:Th1 was $\leq 1$, parenchymal inflammation was largely restricted to the spinal cord. ${ }^{7}$ Therefore, we hypothesized that the Th17: Th1 ratio of myelin protein-specific $T$ cells may influence the extent of lesion burden in the brain vs spinal cord in patients with MS. While previous comparisons between healthy controls (HCs) and patients with MS of the frequency of myelin antigen-specific IFN- $\gamma$ and/or IL-17-producing T cells in peripheral blood mononuclear cells (PBMCs) have been contradictory, ${ }^{8-14}$ no study has investigated $\mathrm{T}$ cell responses to myelin antigens in patients stratified according to neuroinflammatory patterns. We investigated the frequency of $\mathrm{T}$ cells secreting these cytokines following stimulation with myelin basic protein (MBP) or myelin oligodendrocyte glycoprotein (MOG) in PBMCs from patients with RRMS who had lesions localized predominantly in the brain or the spinal cord. Strikingly, the cytokine responses differed when triggered by exposure to different myelin antigens, and the combined responses to both myelin antigens defined distinct $T$ cell signatures that distinguished patients with MS who had different neuroinflammatory patterns. These results suggest that regional lesion localization may be associated with myelin-specific $\mathrm{T}$ cells with different properties.
METHODS Patients and HCs. Cryopreserved PBMCs were obtained from the Immune-Mediated Disease Registry maintained at the Benaroya Research Institute (BRI) ${ }^{15}$ from patients with RRMS exhibiting lesions primarily in the brain ("brain-predominant," $\mathrm{n}=29$ ) or predominantly in the spinal cord ("spinal cord-predominant"; a total of 16 matching our criteria were available in the registry) based on MRI at the time of blood draw. Only patients with MRI lesions typical of MS in morphology and location (infratentorial, juxtacortical, periventricular, spinal cord) ${ }^{16}$ were included (see table e-1 at Neurology.org/nn for patient and HC demographics). Brain scans were graded as follows: $0=$ normal brain, $1=$ all nonspecific lesions, $2=1$ lesion, $3=2-4$ lesions, $4=5-8$ lesions, and $5=>8$ typical MS lesions. Spinal cord scans were graded by the cumulative area of spinal cord segments affected by MS lesions. A priori definition of brain-predominant MS required a brain grade of 3-4 with $\leq 0.5$ affected spinal cord segments or brain grade of 5 with $\leq 1$ affected cord segment. Spinal cord-predominant MS was defined as brain grade of 1 with $\geq 2$ affected cord segments, brain grade of 2 with $\geq 2.5$ affected cord segments, brain grade of 3 with $\geq 6$ affected cord segments, or brain grade 4 with $\geq 12$ affected cord segments. Characteristics of MRI scans for the 2 cohorts are shown in table 1. No differences between patients with MS who had brain-predominant vs spinal cord-predominant lesions were seen in the distribution of 33 different HLA-DRB1 alleles (including HLA-DRB1*1501 and DRB1*0401) and 15 HLADQB1 alleles that are routinely analyzed when patients enter the registry (data not shown). Only patients who were within 5 years of diagnosis of MS and not treated with disease-modifying agents for at least 3 months before time of blood draw were selected for the study. Historically, only 3 brain-predominant patients and zero spinal cord-predominant patients had ever been on immune-modifying therapy. Only 3 brain-predominant and 2 spinal cord-predominant patients exhibited clinical signs at time of blood draw. Neuromyelitis optica was ruled out in spinal cord-predominant patients based on lesion characteristics observed on MRI; patients with spinal cord lesions affecting $>3$ spinal cord segments were excluded. Consistent with a diagnosis of MS, all spinal cord-predominant patients exhibited some brain lesions. Age-, ethnicity- and sex-matched HCs $(\mathrm{n}=45)$ had no history of autoimmunity or signs of infection at time of blood draw. Demographics of the patients and controls including Expanded Disability Status Scale scores are shown in table e-1.

\begin{tabular}{|c|c|c|c|c|c|c|}
\hline \multirow{3}{*}{$\begin{array}{l}\text { Table } 1 \\
\text { MRI brain } \\
\text { grade }\end{array}$} & \multicolumn{6}{|c|}{ MRI-based criteria used to identify patients with brain-predominant and spinal cord-predominant MS } \\
\hline & \multicolumn{3}{|c|}{ Brain-predominant $(n=29)$} & \multicolumn{3}{|c|}{ Spinal cord-predominant $(n=16)$} \\
\hline & No. & $\begin{array}{l}\text { Median no. of } \\
\text { spinal cord } \\
\text { segments with } \\
\text { lesions }\end{array}$ & $\begin{array}{l}\text { Range in no. of } \\
\text { spinal cord } \\
\text { segments with } \\
\text { lesions }\end{array}$ & No. & $\begin{array}{l}\text { Median no. of } \\
\text { spinal cord } \\
\text { segments with } \\
\text { lesions }\end{array}$ & $\begin{array}{l}\text { Range in no. of } \\
\text { spinal cord } \\
\text { segments with } \\
\text { lesions }\end{array}$ \\
\hline 5 & 17 & 0 & $0-1.0$ & 0 & NA & NA \\
\hline 4 & 7 & 0 & 0 & 1 & 12 & NA \\
\hline 3 & 5 & 0 & $0-0.5$ & 4 & 7.5 & $6-11.0$ \\
\hline 2 & 0 & NA & NA & 3 & 3.5 & $2.5-7.0$ \\
\hline 1 & 0 & NA & NA & 8 & 5 & $2.0-8.0$ \\
\hline
\end{tabular}

Abbreviations: MS = multiple sclerosis; NA = not applicable.

Patients with MS were initially stratified according to severity of lesion burden in the brain as described in the methods section and then evaluated for the number of affected spinal cord segments. The combinations of brain and spinal cord features used to define patients with brain-predominant and spinal cord-predominant MS are indicated. 
Standard protocol approvals, registrations, and patient consents. Written informed consent was obtained under protocols approved by the institutional review board at BRI before inclusion in this study.

Enzyme-linked immunosorbent spot assays. All assays were performed in a blinded manner. Ninety-six-well plates (MSIP4W10; Millipore Corp., Billerica, MA) were coated with $3 \mu \mathrm{g} / \mathrm{mL}$ anti-IFN- $\gamma$ (clone MD-1) or anti-IL-17A (clone eBio64CAP17) antibodies (eBioscience, San Diego, CA). PBMCs were thawed at $37^{\circ} \mathrm{C}$, resuspended in roomtemperature fetal bovine serum, overlaid with phosphatebuffered saline, pelleted, washed, and resuspended in complete RPMI (Roswell Park Memorial Institute medium) media with $10 \%$ human serum. PBMCs were plated at $5 \times 10^{5}$ cells/well (IFN- $\gamma$ assay) or $1 \times 10^{6}$ cells/well (IL-17A assay) either alone (background) or with $50 \mu \mathrm{g} / \mathrm{mL}$ human MBP (cat. no. MO689; Sigma-Aldrich, St. Louis, MO), $50 \mu \mathrm{g} / \mathrm{mL}$ recombinant human MOG (residues 30-154, cat. no. 228-11134-3; RayBiotech, Norcross, GA), or tetanus toxoid $(5 \mu \mathrm{g} / \mathrm{mL}$; Astarte, Bothell, WA). Myelin antigen-specific responses were assayed in triplicate, media alone, and tetanus toxoid-specific responses in duplicate, and single wells of PBMCs were stimulated with antiCD3/anti-CD28 antibodies ( $5 \mathrm{ng} / \mathrm{mL}$; eBioscience). Plates were incubated for 24 (IFN- $\gamma$ ) or 48 (IL-17A) hours at $37^{\circ} \mathrm{C}$, washed, and incubated with biotinylated detection antibodies (eBioscience) for 1 to 2 hours, followed by streptavidin alkaline phosphatase (cat. no. 7100-04; SouthernBiotech, Birmingham, AL) for 1 hour. Plates were developed using the Vector Blue AP substrate kit (Vector Laboratories, Burlingame, CA); spots were counted and analyzed using the CTL ImmunoSpot analyzer (Cellular Technology Ltd., Shaker Heights, OH). Background spots were subtracted before calculating the frequency of specific spots. In some experiments, PBMCs were incubated with $10-50 \mu \mathrm{g} / \mathrm{mL}$ of pan-MHC class I blocking antibody (clone W6/32; eBioscience) or $10 \mu \mathrm{g} / \mathrm{mL}$ of anti-HLA-DR (clone L243) and anti-HLA-DQ (clone SPVL3) on ice for 30 to 60 minutes before adding myelin antigen. Low interassay variance was demonstrated by repetitive analyses of $10 \mathrm{HCs}$ for their responses to tetanus toxoid in 4 independent assays. Quadruplicate values for the $10 \mathrm{HCs}$ had an $R^{2}$ range from 0.85 to 0.95 , with a mean correlation $R^{2}$ value of 0.91 (Spearman rank coefficient correlation), demonstrating very good replication of results.

Statistics. Analyses were performed using GraphPad Prism 6 (GraphPad Software, La Jolla, CA). The Mann-Whitney test was used to compare frequencies of myelin-specific cells and ratios of Th17:Th1 cells between groups. A Wilcoxon test was used for interantigen comparisons of Th1 and Th17 responses from the same patients. Two-way analysis of variance with Tukey multiple comparison test was used for MHC class I- and class II-blocking experiments. To test for normal distribution, a D'Agostino and Pearson omnibus normality test was utilized. A $p$ value of $<0.05$ was considered to be statistically significant. A multiple imputation procedure ${ }^{17}$ was used to address the missing MOG-specific cytokine values in the logistic regression models, and $95 \%$ confidence intervals for these models were calculated from a nonparametric bootstrap (resampling) procedure. ${ }^{18}$

RESULTS MBP-specific Th1 but not Th17 responses differ between subsets of patients with MS. To test our hypothesis that myelin antigen-specific Th17:Th1 ratios would differ for patients with MS who had brain- predominant vs spinal cord-predominant lesions, we analyzed PBMCs from HCs and patients with RRMS who exhibited lesions either predominantly in the brain or in the spinal cord (see methods and table 1 for patient classification). All patients were within 5 years of diagnosis of MS and the average number of years since first experiencing a symptom associated with MS was similar for the patient subsets: 5.9 years for the brainpredominant group and 5.2 years for the spinal cordpredominant group. We analyzed PBMCs in a blinded manner using enzyme-linked immunosorbent spot to determine directly ex vivo the number of cells that secreted IFN- $\gamma$ and IL-17 following stimulation with MBP. A significantly higher frequency of MBP-specific IFN- $\gamma^{+}$cells was detected in brain-predominant patients compared to both HCs and spinal cord-predominant patients (figure 1A). Unexpectedly, few PBMCs from the patients with spinal cord-predominant MS produced IFN- $\gamma$ in response to MBP. Approximately half $(7 / 16)$ of the spinal cord-predominant patients generated no MBP-specific IFN- $\gamma^{+}$response above background, even though comparable IFN- $\gamma^{+}$ responses to stimulation with tetanus toxoid or antiCD3/CD28 antibodies were observed among all groups (figure e-1). The number of MBP-specific spots was reduced $46 \%$ to $78 \%$ when PBMCs were preincubated with pan anti-human MHC class IIblocking antibodies, but no decrease was observed following preincubation with pan-MHC class Iblocking antibodies (figure e-2), indicating that the myelin antigen-specific responses detected in these assays reflect $\mathrm{CD}^{+} \mathrm{T}$ cell activity. No correlation was seen between the number of MBP-specific spots and spots detected after anti-CD3/CD28 stimulation, indicating that variation in $\mathrm{T}$ cell number among PBMC samples did not influence quantification of antigen-specific responses. Of note, the frequency of MBP-specific IL- $17^{+}$cells was not different among the 3 groups (figure $1 \mathrm{~B}$ ). Therefore, the MBP-specific Th17:Th1 ratio was significantly higher for patients with spinal cord-predominant MS compared to both patients with brain-predominant MS and HCs because of the minimal MBP-specific IFN- $\gamma^{+}$response observed for the spinal cord-predominant patient group (figure 1C).

T cells exhibit different effector responses to MOG vs MBP. We next analyzed $T$ cell responses to human MOG using PBMC samples from the same blood draw as the PBMCs used to analyze MBP-specific responses. Additional samples from the same blood draw were available for 16 of $45 \mathrm{HCs}, 16$ of 29 brain-predominant, and 13 of 16 spinal cordpredominant patients with MS. Similar to MBPspecific responses, patients with brain-predominant MS trended toward a higher frequency of MOG- 
A

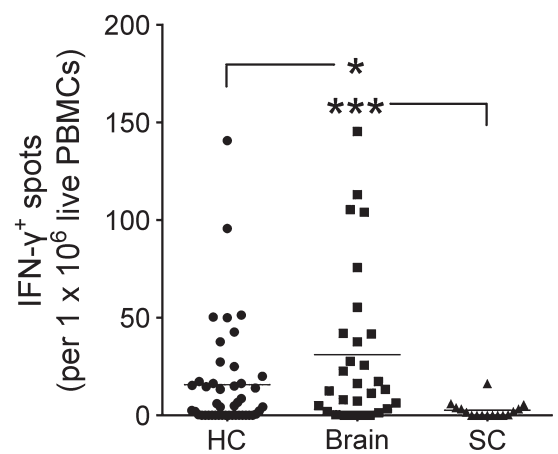

B

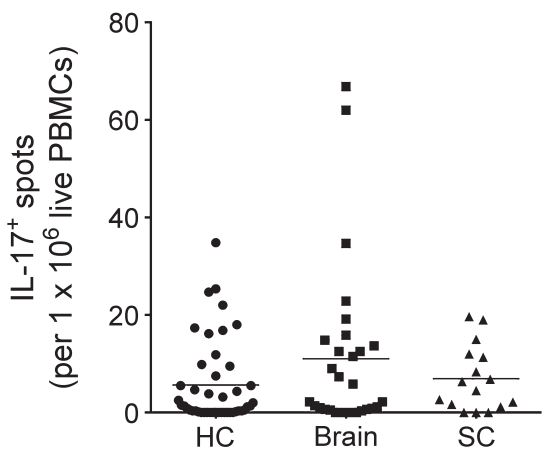

C

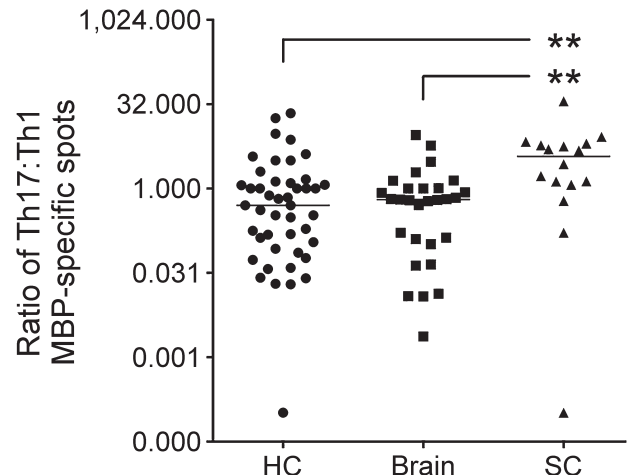

PBMCs from HCs $(n=45)$, brain-predominant $(n=29)$ and spinal cord-predominant $(n=16)$ patients with MS were analyzed for (A) IFN- $\gamma$ or (B) IL-17 MBPspecific responses by enzyme-linked immunosorbent spot. (C) The ratio of Th17:Th1 cells was calculated for each subject and plotted on a log 2 axis. If the denominator (Th1) was 0 , the value was changed to 0.333 based on the lowest possible calculated spot number being 1 spot above background/triplicate wells. * $<<0.05, * * p<0.01, * * * p<0.001$, Mann-Whitney test, 2-sided. $\mathrm{HC}=$ healthy control; IFN = interferon; IL = interleukin; MBP = myelin basic protein; $\mathrm{MS}=$ multiple sclerosis; PBMCs = peripheral blood mononuclear cells; $\mathrm{SC}=$ spinal cord .

specific IFN- $\gamma^{+}$spots compared to both HCs and spinal cord-predominant patients (figure 2A). However, the MOG-specific responses in patients with spinal cord-predominant MS differed from their MBP-specific responses. In contrast to their minimal MBP-specific IFN- $\gamma^{+}$responses, the frequency of MOG-specific IFN- $\boldsymbol{\gamma}^{+}$cells was similar between patients with spinal cord-predominant MS and HCs. Furthermore, the frequency of MOGspecific IL $-17^{+}$cells in patients with spinal cordpredominant MS was significantly higher compared to patients with brain-predominant MS. The MOGspecific Th17:Th1 ratio was again significantly higher for spinal cord-predominant compared to brain-predominant patients with MS (figure 2C), although the factors that caused these higher ratios differed between the MBP- and MOG-specific responses. For MBP-specific responses, the major influence was the low IFN- $\gamma$ response detected for patients with spinal cord-predominant MS. For MOG-specific responses, increased $\mathrm{IL}-17^{+}$cells in patients with spinal cord-predominant MS and increased IFN- $\gamma^{+}$cells in patients with brainpredominant MS were the driving factors in Th17: Th1 ratios.

A comparison of myelin protein specificities among Th1 and Th17 cells demonstrated that Th1 cells were predominantly MOG-specific in all 3 groups (figure 3). In contrast, Th17 cells were not biased toward MOG specificity. Patients with spinal cord-predominant MS and HCs exhibited a more even distribution between MBP and MOG

Figure 2 MOG-specific IL-17+ spots were significantly higher in patients with spinal cord-predominant MS

A

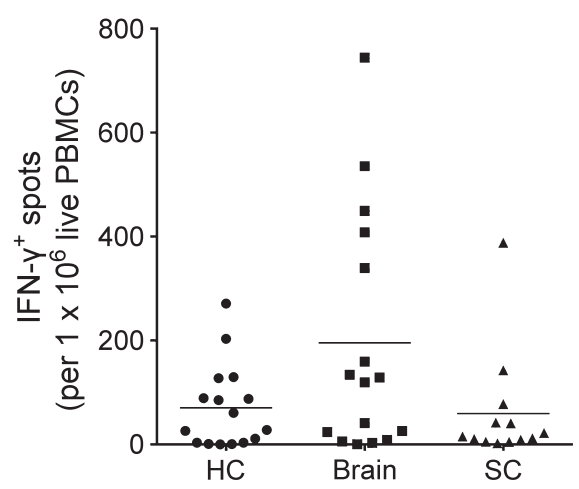

B

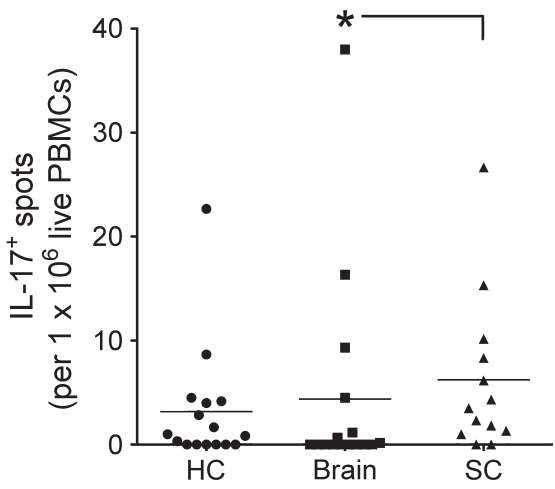

C

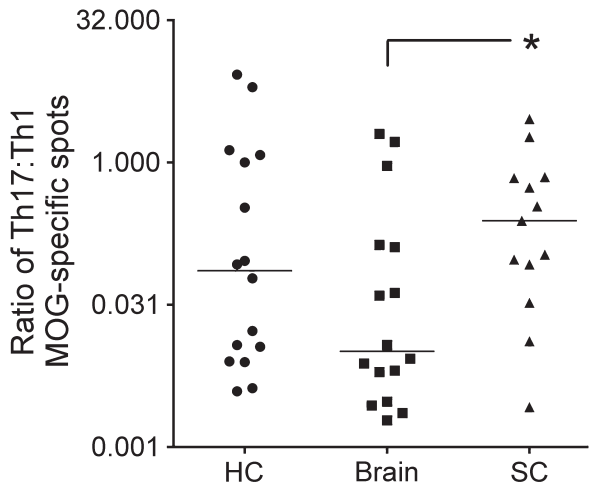

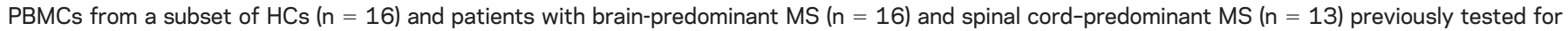

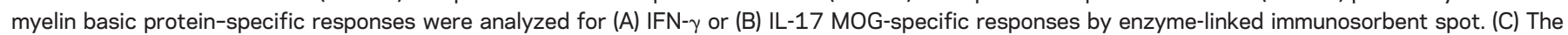

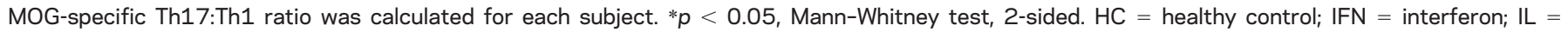
interleukin; MOG = myelin oligodendrocyte glycoprotein; MS = multiple sclerosis; PBMCs = peripheral blood mononuclear cells; SC = spinal cord. 
Figure 3 The relative frequencies of MBP- and MOG-specific T cells differ among Th1 and Th17 effector subsets

A. Healthy controls
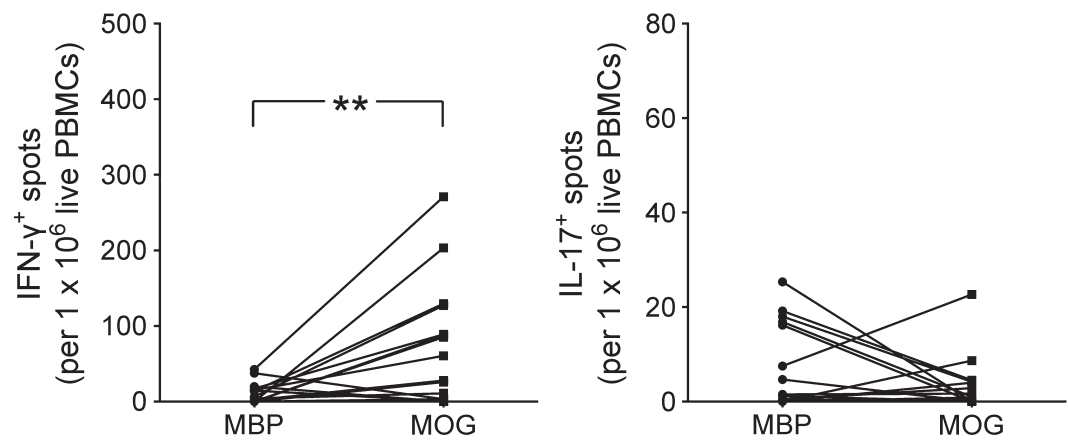

B. Brain
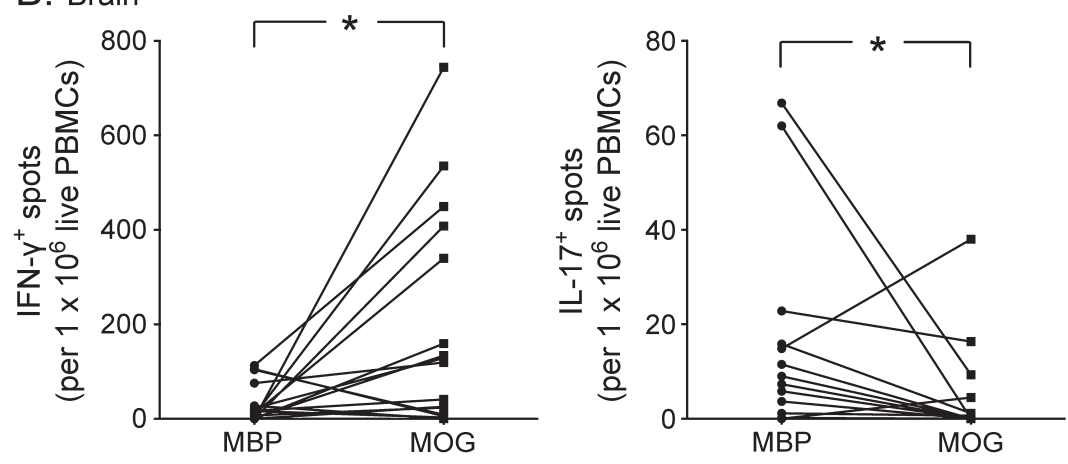

C. Spinal cord
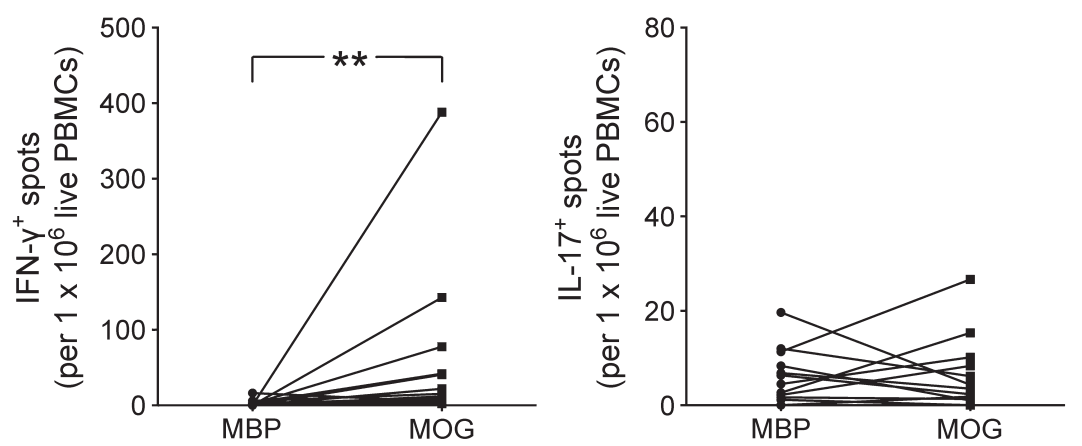

For IFN- $\gamma^{+}$and IL-17+ PBMC responses, the frequencies of MBP-specific vs MOG-specific cells are compared for each individual in (A) healthy control, $(B)$ brain-predominant, or (C) spinal cord-predominant multiple sclerosis patient groups. Asterisks indicate significant differences in the frequencies of MBP- vs MOG-specific responses. $* p<0.05, * * p<$ $0.01, * * * p<0.001$, Wilcoxon test, 2-sided. IFN = interferon; IL = interleukin; MBP = myelin basic protein; MOG = myelin oligodendrocyte glycoprotein; PBMCs = peripheral blood mononuclear cells. antigen-specific responses for all individuals who were analyzed with both myelin antigens. Plotting the frequency of MBP-specific IFN- $\gamma^{+}$vs MOG-specific $\mathrm{IL}-17^{+}$cells for each individual was most effective in separating the data points belonging to spinal cordpredominant patients from brain-predominant patients (figure 4A), highlighting these antigen-specific, effector $\mathrm{T}$ cell responses as being the most disparate between these 2 subsets of patients with MS.

We then generated logistic regression models, which compare 2 groups by generating for each individual in a group a single summary value, or "optimal marker" that optimizes the separation between the groups. Here, the optimal markers for each individual are derived from their MBP- and MOG-specific IFN $-\gamma^{+}$and $\mathrm{IL}-17^{+}$responses. We employed the widely used bootstrap variance methodology to generate values for MOG-specific responses for subjects who were analyzed only for MBP responses because of lack of additional PBMC samples. ${ }^{18}$ Receiver operating characteristic analyses were performed that determine the true-positive rates and false-positive rates of group assignment based on the optimal markers generated by the models. Graphs of the true-positive vs false-positive rates for each 2-group comparison are shown in figure $4 \mathrm{~B}$. The area under the curve (AUC) reflects how well the 2 groups are separated based on their optimal marker values. A perfect separation between groups results in an $\mathrm{AUC}=1$, while no separation between groups results in an AUC $=0.5$. An AUC value $\geq 0.7$ is considered a fair separation while an AUC $\geq 0.9$ is considered very good. The AUC for the comparison of patients with brain-predominant vs spinal cordpredominant MS was 0.83 (95\% confidence interval 0.69-0.98, $p<0.0001)$. The AUC generated by comparison of HCs to patients with spinal cord-predominant MS was 0.70 (95\% confidence interval 0.53-0.87, $p<0.03$ ), while comparison of HCs to patients with brain-predominant MS resulted in the lowest AUC of 0.66 (95\% confidence interval 0.50$0.81, p<0.061)$. These analyses indicate that the combined IFN- $\gamma^{+}$and IL- $17^{+} \mathrm{T}$ cell responses to MBP and MOG provide a good means of discriminating between patients with spinal cord-predominant vs brain-predominant lesions, and that these responses might also distinguish patients with spinal cord-predominant MS from HCs. The responses were less robust in discriminating between patients with brain-predominant MS and HCs.

DISCUSSION We hypothesized from our studies in EAE that differences in effector $\mathrm{T}$ cell frequencies would be observed between subsets of patients with MS that were stratified according to their lesion burden in the brain vs the spinal cord, and that this
Effector $\mathbf{T}$ cell responses distinguish patients with spinal cord-predominant from brain-predominant MS. To determine whether particular cytokine responses per$\mathrm{HC}$ groups, we performed pair-wise comparisons of formed best in discriminating between our patient and

specificities in Th17 cells, while Th17 cells were predominantly MBP-specific among patients with differences in the effector $T$ cell responses elicited by distinct myelin proteins.

Neurology: Neuroimmunology \& Neuroinflammation 
Figure 4 Combined IFN- $\gamma+$ and IL-17+ responses to MBP and MOG reveal distinct cytokine signatures for subsets of patients with MS

A
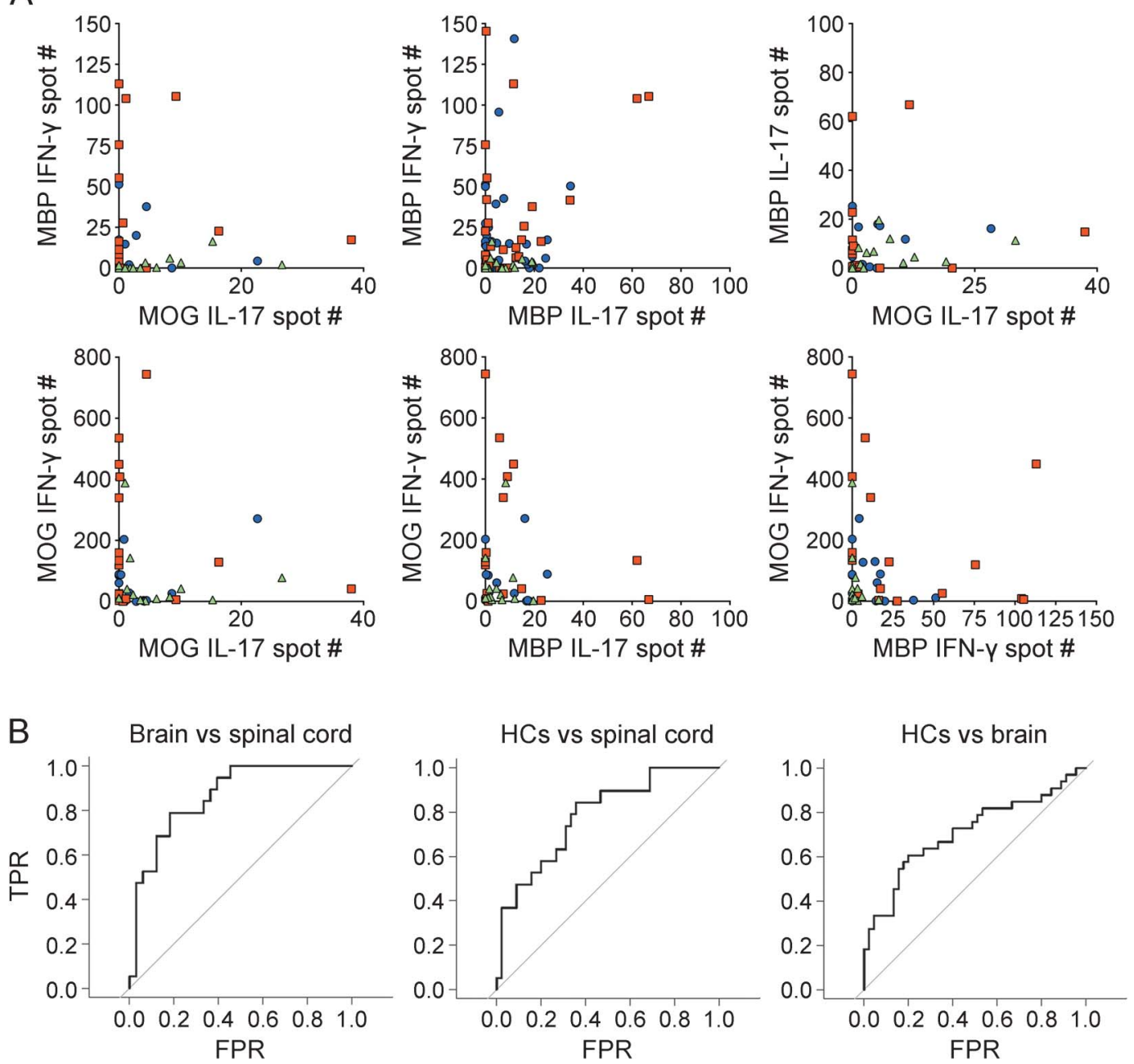

(A) Pair-wise comparisons of the MBP-specific IFN- $\gamma^{+}$, MBP-specific IL-17+, MOG-specific IFN- $\gamma^{+}$, and MOG-specific IL-17+ responses are shown for all HCs (blue circles), patients with brain-predominant MS (red squares), and patients with spinal cord-predominant MS (green triangles) for whom responses to both myelin antigens were determined. (B) ROC analyses were performed to determine how well a diagnostic test using the optimal markers generated from each logistic regression model performed in separating the 2 groups being compared. ROC curves were generated by plotting the TPR vs the FPR as the optimal marker threshold setting is varied. The gray line in each graph represents the results that would be obtained if the test provided no discrimination between groups, i.e., TPR $=$ FPR regardless of the optimal marker value assigned as the threshold that divides the 2 groups. The area under each ROC curve increases as the ability of the test to discriminate between groups increases. FPR = false-positive rate; $\mathrm{HCs}=$ Healthy control; IFN = interferon; IL = interleukin; MBP = myelin basic protein; MOG = myelin oligodendrocyte glycoprotein; MS = multiple sclerosis; ROC = receiver operating characteristic; TPR true-positive rate.

stratification may be necessary to observe differences in effector $\mathrm{T}$ cell frequencies between patients with MS and HCs. To test our hypothesis, we selected patients for analyses of cytokine responses in whom lesions were localized predominantly in the brain or in the spinal cord based on MRI. Our data provide the first evidence that the regional localization of lesions within the CNS in patients with MS is associated with different effector $\mathrm{T}$ cell responses to myelin proteins. Specifically, a low frequency of MBPspecific Th1 cells and a higher frequency of MOGspecific Th17 cells were associated with spinal cord-predominant compared to brain-predominant patients with MS in this study. Consistent with our hypothesis, there is no significant difference in myelin antigen-specific $\mathrm{T}$ cell responses if we combine the data from our 2 MS patient populations into one group and compare it to HCs (figure e-3).

Our finding that MBP and MOG elicited different effector $\mathrm{T}$ cell responses in both MS patient subsets and HCs was unexpected but may explain discrepancies in earlier studies that used different myelin antigens to stimulate PBMCs. Of note, individuals within a group exhibited a similar pattern of 
responses to each myelin antigen, and these patterns differed for the 2 subsets of patients with MS. The ability of myelin antigen-specific $\mathrm{T}$ cell responses to distinguish these cohorts of patients with MS who had spinal cord-predominant lesions from patients who had brain-predominant lesions was illustrated by the receiver operating characteristic analyses of logistic regression models that incorporated all of the $\mathrm{T}$ cell response data. These analyses indicated that the ability to distinguish spinal cord-predominant vs brain-predominant MS was good, and the ability to distinguish patients with spinal cord-predominant MS from $\mathrm{HCs}$ was fair. Of note, discrimination between the HCs and patients with brainpredominant MS was the weakest. It will be important to conduct similar studies on additional patients with MS stratified according to their neuroinflammatory patterns.

The MBP-specific IFN- $\gamma^{+}$response was the most influential measure in determining the optimal marker values generated by the logistic regression models for each 2-group comparison, consistent with the fact that the MBP-specific IFN- $\gamma^{+}$responses exhibited the greatest differences among the 3 groups. Paradoxically, patients with MS who had brainpredominant lesions exhibited significantly higher MBP-specific IFN- $\gamma^{+}$responses compared to $\mathrm{HCs}$ while the MBP-specific IFN- $\gamma^{+}$responses of patients with MS who had spinal cord-predominant lesions exhibited the opposite patterns and trended lower ( $p=0.069)$ compared to HCs, highlighting the difference in $\mathrm{T}$ cell signatures seen in this study between patients with MS who exhibited distinct neuroinflammatory patterns. While other CNS antigens have been implicated in MS, these perturbations in myelin protein-specific $\mathrm{T}$ cell frequencies observed in MS patient subsets support a role for these $\mathrm{T}$ cells in contributing to disease pathogenesis.

One question that arises from our studies is whether $\mathrm{T}$ cell responses detected in PBMCs are indicative of effector $\mathrm{T}$ cell activity within the CNS, or whether peripheral $\mathrm{T}$ cell responses reflect the inverse of $\mathrm{T}$ cell activity within the CNS because the CNS acts as a "sink" for pathogenic T cells. A significantly higher frequency of myelin-specific IFN- $\gamma^{+} \mathrm{T}$ cells was found in the CSF compared to PBMCs in patients with MS ${ }^{10,12,19}$; however, comparisons need to be performed for multiple antigen specificities in individual patients to determine whether there is an inverse relationship or direct correlation between frequencies of peripheral vs CSF myelin-specific $\mathrm{T}$ cells. It is of interest that patients with spinal cord-predominant MS exhibited a higher Th17:Th1 ratio compared to patients with brainpredominant MS for both myelin antigen specificities, although the ratio was influenced by different factors for each myelin protein. Our EAE studies showed that a lower Th17:Th1 ratio preferentially promoted spinal cord parenchymal inflammation, but this finding was based on $\mathrm{T}$ cells isolated from the CNS rather than the periphery. Therefore, if peripheral $\mathrm{T}$ cell responses in humans represent the inverse of responses that would be found in the CNS due to a "sink effect," our findings in humans would be similar to those in mice with EAE.

The key finding from our study is that we identified $\mathrm{T}$ cell cytokine signatures based on production of IFN- $\gamma$ and IL-17 by MBP- and MOG-specific T cells in PBMCs that were associated with patients with MS exhibiting different neuroinflammatory patterns. The higher Th17:Th1 ratio for both MBP- and MOG-specific $\mathrm{T}$ cells in patients with spinal cordpredominant MS could reflect differences in the nature of the pathogenic immune response that leads to different neuroinflammatory patterns in patients with MS. Alternatively, the local environment in the brain vs spinal cord may favor expansion of certain effector $\mathrm{T}$ cells specific for particular antigens over others. Future studies of new cohorts of patients with MS are warranted to confirm and extend the $\mathrm{T}$ cell signatures that we have described here. The ability to distinguish between patients with MS who have predominantly spinal cord vs brain lesions based on peripheral responses to myelin antigens would be valuable in the clinical setting if the type of neuroinflammatory pattern that a patient will develop can be predicted at the time of disease onset or in response to therapy. As spinal cord involvement in MS is a predictor of disability independent of the extent of brain involvement, ${ }^{3}$ prediction of increased lesion burden in the spinal cord may be beneficial. Further understanding of the relationships among $\mathrm{T}$ cell effector function, antigen specificities, and lesion sites may provide new insight into the pathogenic mechanisms that shape neuroinflammatory patterns in patients with MS.

\section{AUTHOR CONTRIBUTIONS}

M.C.J. and E.R.P. helped design the study, performed experiments, analyzed data and helped write the manuscript. A.J.S. analyzed data using logistic regression models. A.S.N. and M.K. evaluated patient MRIs. S.P. coordinated patient data. J.H.B helped design the study and interpret data. J.M.G. designed the study, oversaw the experiments, and wrote the manuscript.

\section{ACKNOWLEDGMENT}

The authors thank the BRI clinical core for the acquisition and handling of patient samples, Catriona Wagner for critical reading of the manuscript, and Michael Mason for consultation related to statistical analysis.

\section{STUDY FUNDING}

This research was supported by grants to J.M.G. from the National Institute for Allergy and Infectious Disease (R37 AI107494-01 and pilot grant support from UO1 AI101990). Initial development of the immunemediated disease registry at BRI was supported by a grant provided by the Life Science Discovery fund of Washington State. 


\section{DISCLOSURE}

M.C. Johnson received research support from the National Institute for Allergy and Infectious Disease (NIAID). E.R. Pierson received research support from NIAID. A.J. Spieker, A.S. Nielsen, and S. Posso report no disclosures. M. Kita received travel funding from Biogen Idec, Genzyme, Novartis, Teva; Virginia Mason Medical Center received honoraria for Dr. Kita's speaker participation from Biogen Idec, Genzyme, Teva; Dr. Kita received research support from Biogen Idec, Novartis, Genentech, Serono, Acorda, Boehringer Ingelheim Pharmaceuticals Inc. J.H. Buckner served on the scientific advisory board for Janssen, Eli Lilly, received travel funding and/or speaker honoraria from TrialNet, Keystone Symposium, FOCIS, University of Texas, Yale, UCSF Diabetes Symposium, Columbia University, UCSF Sean N. Parker Autoimmune Lab Retreat, Eli Lilly, University of Pittsburgh, Harvard, La Jolla Institute for Allergy and Immunology, Karolinska Tolerance workshop, is editor for UpToDate, editor for Science Immunology, holds patents for Method for generating antigen-specific regulatory $\mathrm{T}$ cells, Method for identifying an autoimmune disease, Protein array platform, consulted for Celgene, Janssen, Eli Lilly, received research support from Bristol-Myers Squibb, Eli Lilly, Pfizer, Amgen, Novo Nordisk, NIDDK, NIAID, NIAMS, JDRF, Helmsley Foundation. J. Goverman received travel funding and/or speaker honoraria from National Multiple Sclerosis Society, Federation of American Societies of Experimental Biology, Keystone Symposia, Frederick National Laboratory for Cancer Research and Leidos Biomedical Research, Case Western University, University of California, Irvine, University of California, Merced, University of California, San Francisco, Cleveland Clinic, received research support from NIAID, National Multiple Sclerosis Society. Go to Neurology.org/nn for full disclosure forms.

Received June 1, 2016. Accepted in final form July 20, 2016.

\section{REFERENCES}

1. Thorpe JW, Kidd D, Moseley IF, et al. Spinal MRI in patients with suspected multiple sclerosis and negative brain MRI. Brain 1996;119:709-714.

2. Nociti V, Cianfoni A, Mirabella M, et al. Clinical characteristics, course and prognosis of spinal multiple sclerosis. Spinal Cord 2005;43:731-734.

3. Lukas C, Sombekke MH, Bellenberg B, et al. Relevance of spinal cord abnormalities to clinical disability in multiple sclerosis: MR imaging findings in a large cohort of patients. Radiology 2013;269:542-552.

4. Stoolman JS, Duncker PC, Huber AK, Segal BM. Site-specific chemokine expression regulates central nervous system inflammation and determines clinical phenotype in autoimmune encephalomyelitis. J Immunol 2014;193:564-570.

5. Liu Y, Holdbrooks AT, Meares GP, Buckley JA, Benveniste EN, Qin H. Preferential recruitment of neutrophils into the cerebellum and brainstem contributes to the atypical experimental autoimmune encephalomyelitis phenotype. J Immunol 2015;195:841-852.
6. Lees JR, Golumbek PT, Sim J, Dorsey D, Russell JH. Regional CNS responses to IFN-gamma determine lesion localization patterns during EAE pathogenesis. J Exp Med 2008;205:2633-2642.

7. Stromnes IM, Cerretti LM, Liggitt D, Harris RA, Goverman JM. Differential regulation of central nervous system autoimmunity by $\mathrm{T}(\mathrm{H}) 1$ and $\mathrm{T}(\mathrm{H}) 17$ cells. Nat Med 2008;14:337-342.

8. Huber AK, Wang L, Han P, et al. Dysregulation of the IL-23/IL-17 axis and myeloid factors in secondary progressive MS. Neurology 2014;83:1500-1507.

9. Moldovan IR, Rudick RA, Cotleur AC, et al. Interferon gamma responses to myelin peptides in multiple sclerosis correlate with a new clinical measure of disease progression. J Neuroimmunol 2003;141:132-140.

10. Olsson T, Zhi WW, Hojeberg B, et al. Autoreactive T lymphocytes in multiple sclerosis determined by antigeninduced secretion of interferon-gamma. J Clin Invest 1990;86:981-985.

11. Saez-Torres I, Brieva L, Espejo C, Barrau MA, Montalban X, Martinez-Caceres EM. Specific proliferation towards myelin antigens in patients with multiple sclerosis during a relapse. Autoimmunity 2002;35:45-50.

12. Sun J, Link H, Olsson T, et al. T and B cell responses to myelin-oligodendrocyte glycoprotein in multiple sclerosis. J Immunol 1991;146:1490-1495.

13. Hellings $\mathrm{N}$, Baree $\mathrm{M}$, Verhoeven $\mathrm{C}$, et al. T-cell reactivity to multiple myelin antigens in multiple sclerosis patients and healthy controls. J Neurosci Res 2001;63:290-302.

14. Pelfrey CM, Rudick RA, Cotleur AC, Lee JC, TaryLehmann M, Lehmann PV. Quantification of selfrecognition in multiple sclerosis by single-cell analysis of cytokine production. J Immunol 2000;165:1641-1651.

15. Snir O, Rieck M, Gebe JA, et al. Identification and functional characterization of $\mathrm{T}$ cells reactive to citrullinated vimentin in HLA-DRB1*0401-positive humanized mice and rheumatoid arthritis patients. Arthritis Rheum 2011; 63:2873-2883.

16. Polman CH, Reingold SC, Banwell B, et al. Diagnostic criteria for multiple sclerosis: 2010 revisions to the McDonald criteria. Ann Neurol 2011;69:292-302.

17. Rubin DB. Inference and missing data. Biometrika 1976; 63:581-590.

18. Efron B, Tibshirani R. An Introduction to the Bootstrap. New York: Chapman \& Hall; 1993.

19. Soderstrom M, Link $H$, Sun JB, et al. T cells recognizing multiple peptides of myelin basic protein are found in blood and enriched in cerebrospinal fluid in optic neuritis and multiple sclerosis. Scand J Immunol 1993;37:355-368. 


\section{Neurology \\ Neuroimmunology \& Neuroinflammation}

Distinct $\mathbf{T}$ cell signatures define subsets of patients with multiple sclerosis

Mark C. Johnson, Emily R. Pierson, Andrew J. Spieker, et al.

Neurol Neuroimmunol Neuroinflamm 2016;3;

DOI 10.1212/NXI.0000000000000278

This information is current as of August 23, 2016

\section{Updated Information \& Services}

Supplementary Material

References

Subspecialty Collections

Permissions \& Licensing

Reprints including high resolution figures, can be found at:

http://nn.neurology.org/content/3/5/e278.full.html

Supplementary material can be found at:

http://nn.neurology.org/content/suppl/2016/08/23/3.5.e278.DC1

This article cites 18 articles, 5 of which you can access for free at: http://nn.neurology.org/content/3/5/e278.full.html\#\#ref-list-1

This article, along with others on similar topics, appears in the following collection(s):

Autoimmune diseases

http://nn.neurology.org//cgi/collection/autoimmune_diseases Multiple sclerosis

http://nn.neurology.org//cgi/collection/multiple_sclerosis

Information about reproducing this article in parts (figures,tables) or in its entirety can be found online at:

http://nn.neurology.org/misc/about.xhtml\#permissions

Information about ordering reprints can be found online:

http://nn.neurology.org/misc/addir.xhtml\#reprintsus

Neurol Neuroimmunol Neuroinflamm is an official journal of the American Academy of Neurology.

Published since April 2014, it is an open-access, online-only, continuous publication journal. Copyright $(\subseteq$ 2016 American Academy of Neurology. All rights reserved. Online ISSN: 2332-7812.

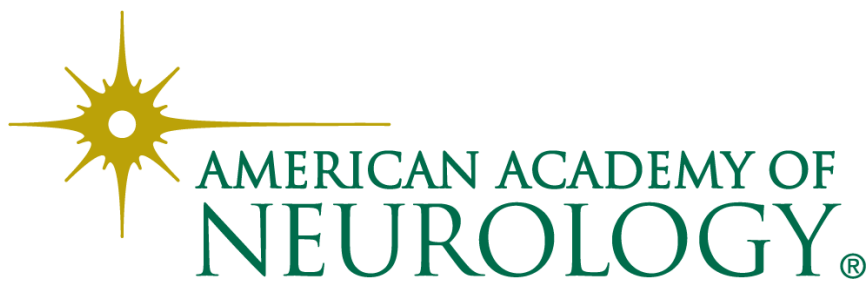

